\title{
Building-level wastewater monitoring for COVID-19 using tampon swabs and RT-LAMP for rapid SARS-CoV-2 RNA detection
}

\author{
Aaron Bivins ${ }^{1,2}$, Megan Lott ${ }^{3}$, Marlee Shaffer ${ }^{1}$, Zhenyu Wu ${ }^{1}$, Devin North ${ }^{1}$, Erin K. Lipp ${ }^{3}$, Kyle \\ Bibby $^{1,2^{*}}$ \\ ${ }^{1}$ Department of Civil \& Environmental Engineering \& Earth Sciences, University of Notre Dame, \\ 156 Fitzpatrick Hall, Notre Dame, IN 46556 \\ ${ }^{2}$ Environmental Change Initiative, University of Notre Dame, 721 Flanner Hall, Notre Dame, IN \\ 46556 \\ ${ }^{3}$ Department of Environmental Health Science, University of Georgia, 150 East Green Street, \\ Athens, GA 30602 \\ *kbibby@nd.edu
}

\section{Abstract}

Community-level wastewater monitoring for severe acute respiratory syndrome coronavirus 2

(SARS-CoV-2) RNA has demonstrated useful correlation with both coronavirus disease 2019

(COVID-19) case numbers and clinical testing positivity. Wastewater monitoring on college campuses has demonstrated promising predictive capacity for the presence and absence of COVID-19 cases. However, to date, such monitoring has largely relied upon composite or grab samples and reverse transcription quantitative PCR (RT-qPCR) techniques, which limits the accessibility and scalability of wastewater monitoring. In this study, we piloted a workflow that uses tampons as passive swabs for collection and reverse transcription loop-mediated isothermal amplification (RT-LAMP) to detect SARS-CoV-2 RNA in wastewater. Results for the developed workflow were available same day, with a time to result following tampon swab collection of approximately three hours. The RT-LAMP 95\% limit of detection (76 gene copies reaction ${ }^{-1}$ ) was greater than RT-droplet digital PCR (ddPCR; 3.3 gene copies reaction ${ }^{-1}$ ). Nonetheless, during a building-level wastewater monitoring campaign conducted in the midst of weekly clinical testing of all students, the workflow demonstrated a same-day positive predictive value (PPV) of $33 \%$

31 and negative predictive value (NPV) of $80 \%$ for incident COVID-19 cases. The NPV is comparable 32 to that reported by wastewater monitoring using RT-qPCR. These observations suggest that even 
33 with lower analytical sensitivity the tampon swab and RT-LAMP workflow offers a cost-effective

34 and rapid approach that could be leveraged for scalable same-day building-level wastewater

35 monitoring for COVID-19.

36

37 Keywords: SARS-CoV-2, wastewater monitoring, environmental surveillance, RT-LAMP,

38 building-level, near-source, passive sampling

39

40

Highlights

41 - RT-LAMP wastewater testing results available three hours after swab collection;

42 - Tampon swab and RT-LAMP same-day NPV of $80 \%$ and PPV of 33\% for COVID-19

43 cases;

44 - Tampon swab and RT-LAMP wastewater monitoring consumables cost less than $\$ 0.25$

$45 \quad$ USD per person monitored;

46

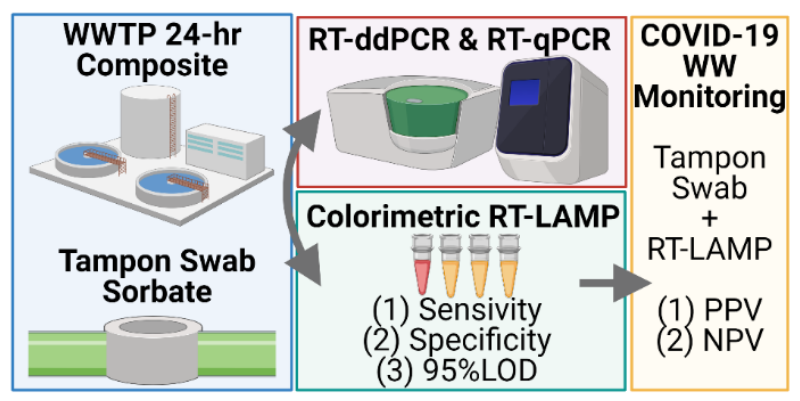

48 


\section{Introduction}

50 Infection with severe acute respiratory syndrome coronavirus 2 (SARS-CoV-2), the etiologic agent

51 of coronavirus disease 2019 (COVID-19), is accompanied by shedding of the virus, including its

52 RNA genome, in upper and lower respiratory tract fluids and feces (Cevik et al., 2021), saliva

53 (Wyllie et al., 2020), and urine (Kashi et al., 2020). Since these body fluids are frequently

54 discharged to wastewater collection networks in domestic sewage, wastewater-based

55 epidemiology (WBE; also called wastewater surveillance or wastewater monitoring) has become

56 a useful tool for assessing community trends of COVID-19 (Bivins et al., 2020). SARS-CoV-2

57 RNA has been detected in untreated wastewater samples throughout the world (Ahmed et al.,

58 2020a; Carrillo-Reyes et al., 2021; Fongaro et al., 2021; Johnson et al., 2021; Medema et al.,

59 2020; Wu et al., 2020). Longitudinal measurements of SARS-CoV-2 RNA in wastewater influent

60 and primary solids at wastewater treatment plants (WWTPs) have been found to correlate with

61 COVID-19 clinical testing metrics in various communities (D'Aoust et al., 2021b; Feng et al., 2021;

62 Gonzalez et al., 2020; Peccia et al., 2020). In many contexts increases in SARS-CoV-2 RNA in

63 wastewater or wastewater solids have preceded increases in COVID-19 cases and

64 hospitalizations by days to weeks (D'Aoust et al., 2021a; Nemudryi et al., 2020; Saguti et al.,

65 2021). Thus, wastewater monitoring offers a complementary method of assessing COVID-19

66 trends in communities that is independent of and perhaps leads clinical testing.

68 While promising, monitoring SARS-CoV-2 RNA in influent at WWTPs lacks the geographic 69 specificity to target clinical testing or other public health interventions at fine scales. Building-level 70 monitoring, on the other hand, could inform clinical testing at specific locations on the basis of 71 wastewater data from individual facilities, such as schools (Hassard et al., 2021) and skilled

72 nursing facilities (Spurbeck et al., 2021). Spurbeck et al. used 24-hour wastewater composite 73 samples and RT-qPCR to detect one infection among 60 skilled nursing facility residents 74 (Spurbeck et al., 2021). Another building-level study at a skilled nursing facility using wastewater 
75 grab samples reported mixed results. Detection of SARS-CoV-2 RNA lagged a three person

76 COVID-19 outbreak by one month at one facility and preceded clinical identification of COVID-19

77 cases by 5 to 19 days in two other facilities (Davó et al., 2021). A recent preprint described the

78 use of near-source tracking via twice weekly composite samples and RT-qPCR to monitor

79 wastewater from 16 schools and showed detection frequency consistent with community COVID-

8019 status (Gutierrez et al., 2021).

82 Wastewater monitoring for SARS-CoV-2 RNA, including build-level monitoring, is being used to 83 manage COVID-19 on university campuses throughout the United States (Harris-Lovett et al., 84 2021). Colleges have deployed wastewater monitoring in conjunction with other public health 85 measures including clinical testing, contact tracing, and isolation (Travis et al., 2021) with 86 wastewater monitoring used to guide clinical testing (Barich and Slonczewski, 2021). At the

87 University of Arizona, wastewater surveillance with serial grab samples identified one 88 symptomatic and two asymptomatic infections in a dorm and provided early warning of infections

89 in a total of 13 dorms over a semester (Betancourt et al., 2021). An innovative high-throughput

90 wastewater monitoring platform allowed for the detection of a single case of COVID-19 among

91415 residents of a dorm at University of California San Diego (Karthikeyan et al., 2021). And

92 another building-level monitoring effort leveraged composite wastewater samples and RT-qPCR

93 performed three times weekly to identify asymptomatic COVID-19 cases on multiple occasions

94 down to one asymptomatic infection among 150 to 200 dorm residents (Gibas et al., 2021).

95

96 Building-level wastewater monitoring could be particularly useful at universities where student

97 behavior (Monod et al., 2021), congregate living (Reukers et al., 2021), and asymptomatic

98 transmission (Bjorkman et al., 2021) could combine to fuel outbreaks. Complicating transmission

99 control are asymptomatic infections, which have been observed to account for $43 \%$ (Lavezzo et

100 al., 2020) to $50 \%$ of infections (Arons et al., 2020) among adults. Since viral loads have been 
101 found to be similar among asymptomatic, pre-symptomatic, and symptomatic patients (Lavezzo 102 et al., 2020; Walsh et al., 2020) and asymptomatic and mild COVID-19 cases have been observed 103 to shed SARS-CoV-2 RNA in stool (Park et al., 2020), wastewater monitoring offers an opportunity

104 to screen for COVID-19 cases among building-level populations and identify cases via follow-up 105 clinical testing (Oran and Topol, 2020).

106

107 While wastewater surveillance offers a compelling tool for building-level COVID-19 detection at 108 universities, most of the reported monitoring efforts have depended on composite samplers to 109 achieve representative samples over a defined time period (usually 24 hours). These samplers 110 can be expensive and difficult to place in building service lines. Other studies have used grab 111 samples, but such samples are "snapshots" and may not afford a reliably representative sample.

112 A few SARS-CoV-2 wastewater monitoring efforts to date, however, have used the Moore Swab, 113 a gauze bundle left suspended in sewers to sorb wastewater and enteric pathogens. This type of 114 passive sampling was first used to detect Salmonella Paratyphi in 1948 (Barrett et al., 1980) and 115 has also been used to detect Vibrio cholerae (Barrett et al., 1980) and enteric viruses (Tian et al., 116 2017) in wastewater. More recently, Moore swabs in combination with RT-qPCR were used to 117 monitor wastewater at a university and were able to detect one to two COVID-19 cases in a 118 building (Liu et al., 2020). The same study found that when used alongside grab samples, the 119 Moore Swab allowed a greater sensitivity for SARS-CoV-2 RNA in wastewater from a hospital 120 treating COVID-19 patients (Liu et al., 2020). Another evaluation of passive samplers (gauze, 121 electronegative filter, and cotton buds) alongside traditional sampling techniques (flow-weighted 122 and time-average composite, and grab samples) found that passive samplers were at least as 123 sensitive over 24-hour deployments and a positive correlation between SARS-CoV-2 RNA 124 concentrations in wastewater and those from passive samplers (Schang et al., 2020). 
126 Passive samplers, such as the Moore Swab, could make wastewater monitoring possible without

127 the use of expensive composite samplers. However, detection and quantification of SARS-CoV-

1282 RNA in wastewater samples has also required the use of RT-qPCR techniques, which depend

129 on specialized PCR equipment such as thermal cyclers. Reverse transcription loop-mediated

130 isothermal amplification (RT-LAMP) (Notomi, 2000) offers the potential to detect SARS-CoV-2

131 RNA in wastewater samples without the use of such equipment. RT-LAMP has been validated for

132 rapid testing of clinical samples including serum, urine, saliva, oropharyngeal swabs, and

133 nasopharyngeal swabs for SARS-CoV-2 RNA (Ganguli et al., 2020; Schermer et al., 2020). A

134 colorimetric RT-LAMP kit developed by New England Biolabs using multiplexed primers targeting

135 the $\mathrm{N}$ and $\mathrm{E}$ regions (N2 and E1) of the SARS-CoV-2 genome had accuracy greater than $90 \%$

136 compared to RT-qPCR and a 95\% limit of detection of 59 copies per reaction when used to test

137 heat treated saliva samples (Lalli et al., 2021). Multiplexing primers and the addition of guanidine

138 chloride was found to increase the sensitivity five- to tenfold for colorimetric LAMP with the N2

139 and E1 primers yielding the best performance among seven primer sets (Zhang et al., 2020). A

140 preprint reported the use of RT-qLAMP with primers targeting the ORF1a, E, and N genes to test

141 wastewater samples for SARS-CoV-2 RNA without extraction in wastewater volumes up to 9.5

$142 \mu \mathrm{L}$ (Ongerth and Danielson, 2020).

144 During the current study, we piloted the application of colorimetric RT-LAMP to detect SARS145 CoV-2 RNA in wastewater from tampon swabs and primary influent from WWTPs in northern 146 Indiana and northeast Georgia using a variety of extraction and processing techniques. We 147 assessed the sensitivity, specificity, and limit of detection of RT-LAMP for wastewater samples 148 compared to RT-qPCR and reverse transcription droplet digital PCR (RT-ddPCR). We then used 149 tampon swabs and RT-LAMP for rapid monitoring of building-level wastewater at the University 150 of Notre Dame over six weeks in conjunction with ongoing public health measures to assess the 151 positive and negative predictive value of these measures. 


\section{2. Materials \& Methods}

154 2.1 Primary influent and raw sewage samples

155 During the experiments performed in Athens, GA, and Notre Dame, IN (USA), 24-hour time-based 156 composite samples of primary influent were collected at eleven wastewater treatment plants 157 (WWTPs): three located in Athens-Clarke County, GA and eight located throughout the state of 158 Indiana. All such samples collected at WWTPs are referred to as "primary influent" throughout. In 159 addition to primary influent, a number of wastewater samples were collected from the wastewater 160 systems at the University of Notre Dame (ND) and neighborhoods within the Athens area, 161 including the University of Georgia (UGA). All samples from wastewater collection systems are 162 referred to as "raw sewage" throughout. Raw sewage samples were collected using two 163 techniques: 24-hour time-based composite samples (for the main sewage discharge manhole at 164 ND) and tampon swab passive samplers (detailed further below). In all cases, immediately after 165 collection, both primary influent and raw sewage samples were stored and transported on ice or 166 at $4^{\circ} \mathrm{C}$ until processed.

\subsection{Tampon Swab Samplers}

169 Tampons were used as low-cost and readily available Moore swabs for passive sampling of raw 170 sewage in the wastewater collection system. At UGA, 100\% organic cotton tampon swabs (OB 171 Brand Organic Tampons, Super) were deployed into the wastewater collection system for 24

172 hours at each sampling location. After recovery, swabs were placed in sterile WhirlPak bags 173 (Nasco, Fort Atkinson, WI) and saturated with $20 \mathrm{~mL}$ of sterile PBS. Saturated swabs were hand 174 massaged for two minutes to elute viruses and then the sorbate was squeezed from the swab 175 and collected in a sterile $50 \mathrm{~mL}$ centrifuge tube for immediate extraction. 
177 At ND, with the assistance of utilities personnel, tampon swabs (Tampax Pearl, Super) were 178 deployed into the wastewater collection system weekly for six weeks from approximately 8:00 am 179 to $11: 00$ am at nine different locations selected to isolate individual residential halls $(\mathrm{RH})$ 180 (anonymized as $\mathrm{RH} 1$ to 9 ). During the monitoring period, these RHs housed 1,627 students 181 accounting for $25 \%$ of the on-campus residents. Upon retrieval from manholes, swabs were 182 placed into sterile WhirlPak bags and stored on ice. In the lab, swabs were hand squeezed while 183 in the WhirlPak bag to remove most of the sorbate and then aseptically placed into a $60 \mathrm{~mL}$ luer184 lock syringe (ML60, Air-Tite Products Co, Virginia Beach, VA). The sorbate remaining in the 185 WhirlPak bag was then poured into the syringe and pressed into a $50 \mathrm{~mL}$ centrifuge tube using 186 the syringe plunger typically resulting in 25 to $35 \mathrm{~mL}$ of sorbate. After the first press, a volume of 187 PBS/Tween20 solution (10 mM sodium phosphate, $0.15 \mathrm{M} \mathrm{NaCl}, 0.05 \%$ Tween 20 ) was pipetted 188 into the syringe (typically 15 to $25 \mathrm{~mL}$ ) such that the total volume of absorbate resulting from each 189 swab was $50 \mathrm{~mL}$ and pressed through the swab into the centrifuge tube. The resulting $50 \mathrm{~mL}$ of 190 sorbate was then immediately concentrated or extracted as described below. For primary influent 191 and raw sewage samples collected at UGA and a subset of samples at ND, no concentration or 192 fractionation was performed prior to extraction. For other samples, various forms of concentration 193 and fractionation as described below were trialed.

\subsection{Electronegative Membrane Concentration}

196 At ND, primary influent samples and some raw sewage composite samples were concentrated 197 using electronegative membrane filtration as described in detail elsewhere 198 (https://dx.doi.org/10.17504/protocols.io.bhiuj4ew). Briefly, a $100 \mathrm{~mL}$ aliquot of well-mixed sample 199 was filtered through a $0.45 \mu \mathrm{m}$ mixed-cellulose ester membrane (Pall Corporation, Port 200 Washington, NY, USA) using a vacuum filtration assembly (Sigma-Aldrich, St. Louis, MO, USA). 201 The membrane was then aseptically rolled into a $2 \mathrm{~mL}$ Garnet bead tube (Qiagen, Hilden, 202 Germany) and frozen at $-80^{\circ} \mathrm{C}$ until homogenization prior to extraction. 
204 2.4 Centrifugal Ultrafilter Concentration

205 A subset of swab sorbate samples from ND were concentrated by passing $15 \mathrm{~mL}$ of sorbate 206 through an Amicon Ultra-15 10 kDa Centrifugal Filter Unit (MilliporeSigma, MA, USA) via a 5,000 $207 \times \mathrm{g}$ spin for 30 minutes. The retentate was resuspended in $1 \mathrm{~mL}$ of PBS/Tween20 solution and $208500 \mu \mathrm{L}$ was transferred into a $2 \mathrm{~mL}$ PowerBead tube containing $0.1 \mathrm{~mm}$ glass beads (Qiagen, 209 Hilden, Germany) for homogenization prior to extraction. Owing to difficulty passing the entire 15 $210 \mathrm{~mL}$ volume through the ultrafilter, this concentration method was abandoned after the first week 211 of sampling.

212

$213 \quad 2.5$ Swab Sorbate Solids Fractionation

214 Since enveloped viruses, including SARS-CoV-2, partition favorably to solids in wastewater (Li et 215 al., 2021; Ye et al., 2016), after abandoning ultrafiltration, swab sorbate samples at ND were 216 processed with emphasis on the solids fraction. Each $50 \mathrm{~mL}$ sorbate volume was subjected to 217 centrifugation at $10,000 \times \mathrm{g}$ for 10 minutes at $4^{\circ} \mathrm{C}$. The supernatant was poured off and the pellet 218 was resuspended using $1 \mathrm{~mL}$ of PBS/Tween20 solution. A $500 \mu \mathrm{L}$ aliquot of the resuspension 219 was transferred into a $2 \mathrm{~mL}$ PowerBead tube containing $0.1 \mathrm{~mm}$ glass beads (Qiagen, Hilden, 220 Germany) for homogenization prior to extraction. For a subset of samples, $15 \mathrm{~mL}$ of the resulting 221 supernatant was concentrated via Amicon as described above.

\subsection{Kit-based RNA Extractions}

224 For samples processed at UGA, RNA was extracted from $280 \mu \mathrm{L}$ aliquots of unconcentrated 225 tampon sorbate and primary influent using a QIAamp Viral RNA Mini Kit (Qiagen, Hilden, 226 Germany). Purified RNA was eluted in $60 \mathrm{uL}$ of PCR-grade water. At ND, DNA and RNA were 227 extracted from tampon sorbate and primary influent using an AllPrep PowerViral DNA/RNA kit 228 (Qiagen, Hilden, Germany). Prior to extraction, membrane filters, Amicon ultrafilter retentate, and 
229 raw sewage and sorbate solids were homogenized by adding $600 \mathrm{uL}$ of PM1 and $6 \mathrm{uL}$ of $\boldsymbol{\beta}$ -

230 mercaptoethanol (MP Biomedicals, Irvine, CA, USA) to the PowerBead tubes. These tubes were

231 bead beat for four rounds of 20 seconds each at $4.5 \mathrm{M} / \mathrm{s}$ on a FastPrep 24 (MP Biomedicals,

232 Irvine, CA, USA). The bead tubes were centrifuged at $13,000 \times \mathrm{g}$ for 1 minute and $500 \mathrm{uL}$ of the

233 resulting supernatant was transferred into a clean $2 \mathrm{~mL}$ microcentrifuge tube and DNA/RNA was

234 extracted per the Qiagen protocol. Purified nucleic acids were eluted in 100 uL of RNase-free 235 water.

236

$237 \quad 2.7$ Heat Extraction \& No Extraction

238 A subset of $1 \mathrm{~mL}$ swab sorbate samples and $1 \mathrm{~mL}$ re-suspended solids samples were subjected

239 to heat extraction by incubation in a heat block at $95^{\circ} \mathrm{C}$ for 15 minutes. After incubation, the 240 samples, contained in $2 \mathrm{~mL}$ microcentrifuge tubes, were centrifuged at $13,000 \times \mathrm{g}$ for 2 minutes 241 and $100 \mathrm{uL}$ of supernatant was transferred to a clean $2 \mathrm{~mL}$ centrifuge tube for testing by RT242 LAMP. A subset of primary influent samples was also tested by RT-LAMP without extraction or 243 pre-treatment.

2.8 RT-ddPCR

246 For samples processed at ND, SARS-CoV-2 RNA was quantified using the BioRad QX200 247 Droplet Digital PCR (ddPCR) System and C1000 Touch Thermal Cycler (Hercules, CA, USA) as 248 previously described in detail (Bivins et al. 2021 preprint). Reverse transcription and droplet digital 249 PCR were performed in a single step using the One-Step RT-ddPCR Advanced Kit for Probes 250 (BioRad, Hercules, CA, USA) using the premixed N1 assay (Liu et al. 2020). RT-ddPCR reactions 251 were prepared in triplicate at a volume of $22 \mathrm{uL}$ consisting of $4 \mathrm{uL}$ sample RNA, $6.45 \mathrm{uL}$ PCR252 grade water, $5.25 \mathrm{uL}$ 4X Supermix, $2.1 \mathrm{uL}$ reverse transcriptase, $1.05 \mathrm{uL}$ dithiothreitol, and 3.15 $253 \mathrm{uL}$ of premixed N1 primers and probes (resulting concentrations of $1000 \mathrm{nM}$ and $250 \mathrm{nM}$, 254 respectively) from Integrated DNA Technologies (Coralville, IA, USA). A 20 uL volume of the 
255 reaction mixture, prepared per the BioRad protocol, was pipette mixed and transferred into the 256 droplet generation step. Following thermal cycling $\left(50^{\circ} \mathrm{C} 60\right.$ minutes; $95^{\circ} \mathrm{C} 10$ minutes; 40 cycles 257 of $95^{\circ} \mathrm{C} 30$ seconds and $59^{\circ} \mathrm{C}$ one minute; $98^{\circ} \mathrm{C} 10$ minutes; $4^{\circ} \mathrm{C}$ hold), droplet fluorescence 258 amplitudes were read, classified as positive or negative, and the N1 copy number calculated using 259 manual thresholding in QuantaSoft Version 1.7.4 (BioRad, Hercules, CA, USA) such that all 260 pertinent negative controls contained no positive droplets.

2.9 Reverse Transcription - Quantitative Polymerase Chain Reaction (qPCR)

263 For samples processed at UGA, SARS-CoV-2 viral RNA was detected and quantified using a two264 step reverse transcription qPCR (RT-qPCR) method. Purified RNA was converted to cDNA using 265 an adapted protocol for Invitrogen M-MLV Reverse Transcriptase (Cat No. 28025013). For a 25 266 uL reaction, sample RNA (3 uL), Random Hexamer (2.5 uM, Cat No. N8080127), dNTP Mix (0.5 $267 \mathrm{uM}$ ), and PCR-Grade H20 (10.25 uL) were prepared in a PCR-grade low-bind strip tube. The 268 reaction was heated to $65^{\circ} \mathrm{C}$ for $5 \mathrm{~min}$ and then chilled at $4^{\circ} \mathrm{C}$. The samples were vortexed and 269 spun briefly, and the following reagents were added to the reaction: M-MLV 5X buffer (1X), M270 MLV RT (125 U), DTT, and SUPERase•In RNase Inhibitor (10 U, Cat No. AM2694) to 25 uL. The 271 final reaction was then incubated under the following conditions: $10 \mathrm{~min}$ at $25^{\circ} \mathrm{C}, 50 \mathrm{~min}$ at $37^{\circ} \mathrm{C}$, 272 and $70^{\circ} \mathrm{C}$ for $15 \mathrm{~min}$.

274 SARS-CoV-2 cDNA copies were quantified by real-time quantitative PCR (qPCR) using TaqMan 275 chemistry (Fast Advanced MasterMix, Cat No. 4444557). The SARS-CoV-2 N1 and N2 genes 276 were quantified using the 2019-nCoV CDC primers and probes synthesized by IDT (Cat No. 277 10006713). Samples were assayed in triplicate. For each reaction, 2 uL of template cDNA was 278 mixed with $10 \mathrm{uL}$ of $2 X$ Taq Fast Advanced MasterMix (Cat No.4444963), $1.5 \mathrm{uL}$ of the IDT SARS279 CoV-2 (2019-nCoV) CDC RUO Primer and Probe Kit (Cat No. 10006713), and PCR-grade water 280 to a total volume of $20 \mathrm{uL}$. Assays were analyzed using a BioRad StepOne under the following 
281 reaction conditions: $95^{\circ} \mathrm{C}$ for $2 \mathrm{~min} ; 40$ Cycles $\times\left(95^{\circ} \mathrm{C}\right.$ for $3 \mathrm{sec}, 55^{\circ} \mathrm{C}$ for $\left.30 \mathrm{sec}\right) ; 4^{\circ} \mathrm{C}$ hold. 282 Standard curves for the N1 and N2 assays were generated from quantification of the SARS-CoV2832 plasmid standard synthesized by IDT (4.12 kbp 2019-nCoV_N_Positive Control, Cat No. 284 10006625). Prior to quantification, the standard was linearized by enzymatic digestion with Scal285 HF (New England BioLabs Cat No. R3122S). A serial dilution of the linearized plasmid was 286 assayed in triplicate.

\subsection{RT-LAMP}

289 SARS-CoV-2 RNA was detected by RT-LAMP using the SARS-CoV-2 Rapid Colorimetric LAMP 290 Assay Kit (Cat No. E2019S) from New England BioLabs (NEB) (Ipswich, MA, USA), a 30-minute $29165^{\circ} \mathrm{C}$ colorimetric assay. The kit includes an internal control (LAMP Primer Mix targeting human 292 RNA rActin) and a SARS-CoV-2 LAMP Primer Mix targeting the N and E genes (N2 and E1, 293 respectively, Table S1). NEB reports positive detections observable down to 50 copies per 294 reaction (NEB Product Specification). Each sample was assayed in triplicate RT-LAMP reactions 295 and in parallel with an internal control for each sample, and positive controls, and negative 296 controls for each experiment. For each reaction, template RNA (4 uL) was mixed with WarmStart 297 Colorimetric LAMP 2X Master Mix with UDG (12.5 uL), LAMP Primer Mix (2.5 uL), guanidine 298 hydrochloride (2.5 uL), and PCR-grade water to a final reaction volume of $25 \mathrm{uL}$. The reaction 299 was vortexed gently and briefly spun down prior to incubation at $65^{\circ} \mathrm{C}$ for 30 minutes. Reactions were cooled at room temperature for $5 \mathrm{~min}$ before reading color change and interpreting the results per the NEB protocol. RT-LAMP results were acceptable if the internal control was 302 successfully detected in each sample, the SARS-CoV-2 positive and negative controls (two each 303 per experiment) were appropriately positive and negative, and the negative extraction controls 304 were negative for both the internal control and SARS-CoV-2. When the internal control was not 305 detected for a sample, the sample was interpreted to be inhibited. 


\subsection{COVID-19 Clinical Surveillance at ND}

308 During the period of wastewater monitoring at ND, COVID-19 safety protocols were in place 309 including universal masking, physical distancing, daily health checks, and asymptomatic and 310 symptomatic COVID-19 testing. COVID-19 testing methods included saliva-based PCR tests, 311 primarily for asymptomatic surveillance, nasal swab PCR tests, and rapid antigen tests. All 312 undergraduate and professional students participated in mandatory weekly surveillance testing.

313 Students testing positive for COVID-19 and their close contacts entered isolation in residential

314 facilities outside of their residence hall. Close contacts were tested by nasal swab PCR test on 315 day four of isolation and rapid antigen test on day seven of isolation. If both tests were negative, 316 close contacts departed isolation on day 7 . If either test was positive, close contacts began a new 317 10-day period of isolation. Students testing positive for COVID-19 completed isolation per United

318 States Centers for Disease Control and Prevention protocols with at least 10 days from symptom 319 onset for symptomatic cases or 10 days from positive test results for asymptomatic cases. 320 Although visitation between residence halls was restricted, the possibility of a non-resident 321 COVID-19 case or convalescent case shedding into the wastewater system of another residence 322 hall cannot be precluded.

324 Deidentified COVID-19 case data including the date of positive test, date of isolation start, and 325 date of isolation end were acquired for the nine residence halls over the wastewater monitoring 326 period. The research protocol was reviewed by the University of Notre Dame Institutional Review 327 Board (21-04-6586). In addition to de-identification of the COVID-19 case data for the study, the 328 residence halls have also been anonymized ( $\mathrm{RH} 1$ to $\mathrm{RH} 9$ ), and the monitoring period has been 329 anonymized by the use of elapsed days ( 0 to 73 ) rather than dates. The wastewater monitoring 330 was performed in coordination with the ND Covid Response Unit. 
333 The RT-LAMP 95\% limit of detection (LOD) was estimated using N1 copy number data (N1, RT-

334 ddPCR) and proportions of RT-LAMP reactions positive along an N1 concentration gradient. A 335 cumulative Gaussian distribution was fit to the gradient and the 95th percentile estimated as 336 detailed elsewhere (Bivins et al., 2021). The true negative rate (specificity) was estimated using

337 RT-ddPCR/qPCR non-detections and paired RT-LAMP classifications. The true positive rate 338 (sensitivity) was estimated using RT-ddPCR/qPCR detections and paired RT-LAMP 339 classifications. The relationship between N1 copy number (RT-ddPCR/qPCR) and RT-LAMP 340 classification was modeled using a simple logistic regression (McDonald, 2015) with statistical 341 significance determined by likelihood ratio test (Fox, 1997) and fit assessed using Tjur's R342 squared (Tjur, 2009). Comparisons between two groups (e.g. inhibition between sample types) 343 were made using Mann-Whitney tests and between multiple groups (e.g. inhibition between 344 extraction methods and positivity rate between sorbate fractions) using Kruskal-Wallis tests with 345 Dunn's post test (Dunn, 1964; Kruskal and Wallis, 1952; Mann and Whitney, 1947). The positive 346 and negative predictive values (PPV, NPV) of wastewater testing by tampon swab and RT-LAMP 347 for COVID-19 cases was estimated for incident COVID-19 cases in the residence hall each day 348 following wastewater monitoring out to seven days. PPV and NPV were estimated across all nine 349 residence halls each week, among single residence halls across all weeks, and across all 350 residence halls and all weeks (Parikh et al., 2008). In this case PPV is the probability of an incident 351 COVID-19 case following a positive wastewater sample, and, conversely, NPV is the probability 352 of no incident COVID-19 cases following a negative wastewater sample. All graphing and 353 statistical analyses associated with the described experiments were performed using GraphPad 354 Prism Version 9.0.0 (GraphPad Software, LaJolla, CA, USA).

\section{$356 \quad$ 3. Results}

357 In total, 153 wastewater samples were tested via RT-LAMP. To characterize the sensitivity, 358 specificity, and analytical sensitivity of RT-LAMP, we used 24-hour composite samples of WWTP 
359 influent $(n=42)$ and raw sewage samples collected via tampon swabs $(n=7)$. To analyze RT-

360 LAMP performance with various extraction and processing methods, we leveraged samples from

361 WWTP composites $(n=43)$ and tampon swabs $(n=78)$. Lastly, during a prospective wastewater

362 monitoring campaign at ND, we used RT-LAMP to test 59 raw sewage samples collected via

363 tampon swabs. One tampon swab could not be recovered because it broke free while deployed

364 in a manhole.

365

\subsection{Analytical sensitivity}

367 Using RT-LAMP positivity and RT-ddPCR N1 copy number data, we estimated the RT-LAMP $36895 \%$ LOD to be 76 gene copies (GC) for a single reaction (95\% Cl: $67-87$ ) using a fitted 369 cumulative Gaussian distribution (Figure $\mathrm{S} 1 ; \mathrm{R}^{2}=0.997$ ). The RT-LAMP 95\% LOD is 370 approximately 20 times our estimate of the N1 RT-ddPCR 95\% LOD (Bivins et al., 2021). NEB 371 reports "positive detection observable down to 50 copies", which is comparable to our estimated

$37267 \%$ LOD (51 GC/reaction). Since the RT-LAMP kit uses N2 and E primers, our N1 LOD estimates

373 are not directly representative of the primers in the kit; however, they do provide an estimate of 374 the RT-LAMP LOD relative to RT-ddPCR.

377 Compared to both RT-qPCR/ddPCR non-detections (N1; $n=13)$, RT-LAMP demonstrated an 378 overall true negative rate (TNR) of $46 \%$. Interestingly, the seven false positives were all in 379 comparison to RT-qPCR non-detections $(n=9)$. Whereas for the four RT-ddPCR non-detections, 380 RT-LAMP demonstrated a TNR of $100 \%$. Sample types among the non-detections included both 381 WWTP influent composites and swab sorbate. The experimental design does not allow us to 382 examine whether the difference in the TNR observed between RT-qPCR (two-step) and RT383 ddPCR (one-step) is attributable to differences in the analytical sensitivities of the PCR methods, 
384 the extraction kits used (Viral RNA MiniKit vs. PowerViral DNA/RNA, respectively), or between 385 the wastewater samples collected at UGA and ND.

\subsection{RT-LAMP True Positive Rate (Sensitivity)}

388 We estimated the true positive rate (TPR) using RT-qPCR $(n=3)$ and RT-ddPCR $(n=27)$ 389 quantifications (N1 target in triplicate) compared to positivity among all RT-LAMP reactions. 390 Across all samples positive for SARS-CoV-2 RNA by RT-qPCR/ddPCR, the RT-LAMP TPR was $39157 \%$. A logistic regression model (Figure S2 B) fit to the data indicated that increasing N1 392 GC/reaction was associated with increasing probability of detection by RT-LAMP performed in 393 triplicate (likelihood ratio test, $p=0.0034)$. However, the model fit was poor $($ Tjur's R-squared = 394 0.24). Nonetheless, the logistic model indicates that the $50 \%$ probability of detection via RT-LAMP 395 performed in triplicate is $18 \mathrm{~N} 1 \mathrm{GC} /$ reaction, while the NEB-reported 50 copies yields an $83 \%$ 396 probability of detection by RT-LAMP performed in triplicate. The receiver operating characteristic 397 curve (Figure S2 C) indicates that when N1 GC/reaction are greater than 13, RT-LAMP is able to 398 achieve $80 \%$ sensitivity while minimizing false positives.

\subsection{No Extraction Inhibition Rate}

401 We attempted extraction-free RT-LAMP on five tampon swab sorbate and four 24-hour composite 402 samples of WWTP influent. The inhibition rate among the five undiluted passive samples was $403100 \%$. The inhibition rate for undiluted composite samples was $100 \%$ when using $7 \mu \mathrm{L}$ or $4 \mu \mathrm{L}$ of 404 input. After 1:10 dilution, no inhibition was observed for $7 \mu \mathrm{L}$ of input. Given the dilution required 405 to remedy inhibition and the resulting $10 x$ increase in the $95 \%$ LOD, we abandoned extraction406 free RT-LAMP as a reliable detection method.

407

$408 \quad 3.5$ Heat Extraction Inhibition Rate 
After heat extraction, $100 \%$ of swab sorbate samples $(n=5)$ were inhibited and remained so even

410 after 1:10 dilution. Among the five solid fraction samples, $100 \%$ were inhibited after heat

411 extraction, and $40 \%$ remained so even after 1:10 dilution. Given the high rate of inhibition, we

412 abandoned heat extraction as a reliable method for detection in wastewater via RT-LAMP.

\subsection{Viral RNA Mini versus PowerViral DNA/RNA Inhibition Rate}

415 Lastly, we assessed the rate of RT-LAMP inhibition for samples extracted using the Viral RNA 416 Mini Kit (UGA) and PowerViral DNA/RNA Kit (ND). For 24-hour WWTP influent composite 417 samples $(n=9)$, no inhibition was observed following extraction with the Viral RNA Mini kit. But 418 we observed a $60 \%$ inhibition rate for sorbate from swabs deployed for 24 hours extracted with 419 the same kit $(n=5)$. The inhibition rate for the passive samples was significantly greater than the 420 rate for the composite samples (Figure S3 A; $p=0.0275$ ). Among 24-hour WWTP influent 421 composite samples extracted with the PowerViral kit $(n=33), 18 \%$ were inhibited. While for 422 sorbate, sorbate solid fraction, and sorbate liquid fraction samples $(n=68)$ from swabs deployed 423 for four hours, the PowerViral Kit produced an inhibition rate of $4 \%$. The inhibition rate was 424 significantly lower for passive samplers than composite samples extracted via PowerViral (Figure

425 S3 B; $p=0.0317)$. As shown in Figure S4, the difference in inhibition rates between the Viral RNA 426 Mini Kit and PowerViral DNA/RNA kit was not statistically significant for composite samples (panel 427 A) or for all samples (panel C). We did observe a significantly lower rate of inhibition for swab 428 samples extracted via PowerViral compared to Viral RNA Mini (Figure S4 B; $p=0.0030$ ). 429 However, this difference could also be attributable to the deployment of swabs for 24 hours at 430 UGA (Viral RNA Mini) compared to only four hours at ND (PowerViral).

\section{$432 \quad 3.7$ Tampon Swab Sorbate Processing}

433 To optimize the workflow for SARS-CoV-2 RNA detection in wastewater via RT-LAMP, we 434 assessed the rates of inhibition and positivity between Amicon-concentrated swab sorbate, the 
435 solid fraction of swab sorbate, and the liquid fraction of swab sorbate during two weeks of

436 wastewater monitoring at ND. During the first week, Amicon-concentrated sorbate extracted via

437 PowerViral produced no inhibited RT-LAMP reactions and an overall SARS-CoV-2 RNA positivity

438 of $40 \%$ (11 of 27 RT-LAMP replicates) in samples collected from nine RHs. However, filtering the

439 swab sorbate through the Amicon ultrafilters required several hours of centrifugation. Given our

440 interest in a rapid testing procedure, the following week the swab sorbate was first centrifuged,

441 then the resulting supernatant was concentrated via Amicon and extracted with PowerViral. The

442 solid fraction pellet was also extracted via PowerViral. The rate of RT-LAMP inhibition among the

443 extracted supernatant samples was $38 \%$ and SARS-CoV-2 RNA was not detected in any of 24

444 RT-LAMP replicates. For the extracted solid fractions, there was no inhibition observed and the

445 SARS-CoV-2 RNA positivity was 33\% among 30 RT-LAMP replicates. Both the Amicon-

446 concentrated and solids fraction samples exhibited lower rates of inhibition (Figure S5 A) and

447 higher rates of SARS-CoV-2 positivity (Figure S5 B) than the liquids fraction. Since inhibition rates

$448(p>0.9999)$ and SARS-CoV-2 RNA positivity rates $(p>0.9999)$ were comparable between

449 Amicon-concentrate and solid fraction, we elected to continue monitoring at ND using only the

450 swab sorbate solid fraction to allow for faster processing.

\subsection{COVID-19 Clinical Data}

453 During the observation period, 143,884 COVID-19 clinical tests (symptomatic and asymptomatic)

454 were performed at ND. During the wastewater monitoring (day 31 to 66), an average of 13,748

455 clinical tests were performed each week (Figure S6). The COVID-19 positivity and case number

456 trends among the subpopulation accounted for in sewage monitoring (Figure S7) are similar to

457 the trends for the entire campus. The proportion of wastewater RT-LAMP tests that were positive

458 decreased abruptly from $30 \%$ to 0 from week 3 to week 4 , and then increased slightly in the

459 following two weeks. As shown in Figure S8, this abrupt shift in wastewater positivity could not be

460 explained by a shift in domestic water use. Water use patterns in three of the RHs remained 
consistent across these weeks of wastewater sampling with 19 to $23 \%$ of the daily water use occurring during the 8 am to 11 am wastewater monitoring period.

\subsection{RT-LAMP PPV and NPV for COVID-19}

465 RT-LAMP wastewater testing results (proportion of positive RT-LAMP replicates), COVID-19 466 clinical positives, residents exiting the $\mathrm{RH}$ for isolation, and residents returning from isolation are 467 shown for each RH in Figure 1. RT-LAMP positives in wastewater were coincident with COVID46819 cases on the same day on four occasions $(\mathrm{RH} 1, \mathrm{RH} 2, \mathrm{RH} 7, \mathrm{RH} 9)$. For two residence halls 469 (RH4, RH6) RT-LAMP results were negative across the entire sampling period with one occurring 470 on the same day as a positive COVID-19 clinical test in RH4. There were also RT-LAMP positives 471 during periods without incident COVID-19 cases in $\mathrm{RH} 2, \mathrm{RH} 3, \mathrm{RH}$, and $\mathrm{RH} 9$.

473 Although the ND COVID-19 Response Unit was informed of the wastewater sampling results, the 474 clinical surveillance testing was performed independently and thus allows for an estimation of the 475 tampon swab and RT-LAMP wastewater testing PPV and NPV. PPV and NPV were calculated 476 for each day from the day of wastewater testing (day 0) out to six days after. The PPVs displayed 477 a wider range across residence halls (0 to 100\%; Figure S9 A) than weeks (0 to $75 \%$; Figure S9 478 C). In general, PPV increased from the day of wastewater monitoring to three days after as 479 incident COVID-19 cases increased in the days following. PPV could not be estimated for RH4, $480 \mathrm{RH} 6$, or week 4 monitoring since there were no positive wastewater results. NPV displayed a 481 similar pattern of variation with the range observed between residence halls (0 to $100 \%$ ) being 482 greater than the range between weeks of monitoring (22 to 100\%). NPV decreased from the day 483 of wastewater monitoring out to three days as incident COVID-19 cases increased.

485 Across all residence halls and weeks, tampon swab and RT-LAMP wastewater monitoring, with 486 any replicate positive classified as a positive wastewater result, displayed a PPV of 19 to $38 \%$ 
487 during the six days following wastewater testing (Figure 2A). As shown in Figure 2B, NPV was 488 greater with a maximum of $78 \%$ on the day of wastewater testing to a day six minimum of $38 \%$. 489 The PPV of wastewater testing could be adversely affected by positive RT-LAMP results 490 attributable to convalescent COVID-19 cases returning to residence halls after isolation. As shown 491 in Figure S9, there were six instances where RT-LAMP replicates were positive despite no 492 incident COVID-19 cases, but with returning convalescent cases in the prior seven days. In these 493 six instances, it required four or more convalescent cases before 2 of 3 RT-LAMP replicates were 494 positive, suggesting that a cutoff value of $67 \%$ positivity ( 2 of 3 replicates) could increase the PPV 495 of the wastewater method. As shown in Figure 2A, PPV is increased to $33 \%$ when 2 of 3 positive 496 RT-LAMP reactions are required to classify a sample as positive. This change in cutoff value 497 leaves the NPV largely unchanged (Figure 2B). If the detection of convalescent COVID-19 cases 498 by wastewater sampling is considered a true positive (e.g., the true detection of SARS-CoV-2 499 RNA shed into the wastewater system), then the PPV improves to $56 \%$ on day 0 up to $75 \%$ by 500 day three after wastewater monitoring (Figure S11).

501

502 4. Discussion

503 4.1 Reliable RT-LAMP Workflow and Analytical Performance

504 To develop more accessible wastewater monitoring techniques, we piloted and characterized the 505 performance of a monitoring protocol that makes use of tampon swabs and RT-LAMP to detect 506 SARS-CoV-2 RNA in building-level wastewater. The 95\% LOD for a single RT-LAMP reaction 507 was 20 times higher than the RT-ddPCR N1 assay 95\% LOD. Several studies have found that 508 SARS-CoV-2 RNA shedding in feces can outlast nasopharyngeal shedding in up to $50 \%$ of 509 COVID-19 patients (Elbeblaw, 2020; Jones et al., 2020; Wang et al., 2020). In such cases, the 510 higher RT-LAMP LOD could be advantageous by allowing for convalescent cases to go 511 undetected, while newly incident COVID-19 cases could still be detected. RT-LAMP 512 demonstrated an overall sensitivity of $57 \%$ compared to PCR methods, and a specificity of $100 \%$ 
513 compared to one-step RT-ddPCR. Unfortunately, we were not able to replicate the findings of an

514 earlier pre-print study as all of our attempts to test wastewater directly were inhibited (Ongerth

515 and Danielson, 2020). Our attempts at heat extraction were also consistently inhibited despite the

516 success with saliva and other clinical samples (Mahmoud et al., 2021). We found that regardless

517 of the wastewater type (influent composite or swab sorbate) the use of an extraction kit for testing

518 by RT-LAMP was important to produce uninhibited results.

520 When paired with tampon swab sorbate, the Qiagen AlIPrep PowerViral DNA/RNA Kit yielded a

$5214 \%$ inhibition rate among all samples. Concentrating sorbate with Amicon ultrafilters proved

522 burdensome due to clogging. Since wastewater solids have been proposed as an efficient and

523 sensitive partition for SARS-CoV-2 RNA detection (D'Aoust et al., 2021b; Kitamura et al., 2021),

524 we opted to abandon Amicon concentration in favor of testing the sorbate solids fraction. We

525 found that the solids fraction yielded a comparable SARS-CoV-2 positivity and inhibition rate to 526 ultrafilter concentrate.

4.2 RT-LAMP predictive capability compared to RT-qPCR studies

529 The optimized tampon swab and RT-LAMP workflow yielded a same-day PPV of 33\% and an

530 NPV of $80 \%$ in six weeks of wastewater monitoring. Accounting for the detection of convalescent

531 cases improves the PPV to $56 \%$. The PPV we observed was much lower than the $82 \%$ reported

532 during another study leveraging PEG precipitation and RT-qPCR, but the NPV we observed $(80 \%$

533 versus $88.9 \%$ ) was comparable (Betancourt et al., 2021). The specificity of the tampon swab and

534 RT-LAMP method for COVID-19 cases was $80 \%$, which is better than the $52 \%$ specificity reported

535 for an ultracentrifugation and RT-qPCR method that did not distinguish new infections from

536 convalescent (Colosi et al., 2021). Thus, the tampon swab and RT-LAMP approach may offer a

537 specificity and NPV comparable to more sophisticated monitoring methods. Several

538 epidemiological modeling studies have suggested that an optimal strategy for managing COVID- 
53919 on college campuses should include high-frequency screening tests that are highly specific

540 (Lopman et al., 2021; Paltiel et al., 2020). Our observations indicated that the NPV and PPV for

541 tampon swab and RT-LAMP monitoring were maximized with wastewater monitoring daily to

542 every three days.

543

\section{$544 \quad 4.3$ Rapidity of RT-LAMP results}

545 These models have also consistently emphasized rapid results reporting over sensitivity as a 546 critical feature of effective screening. Wong et al. found that wastewater monitoring with one day

547 to results and four days or less to follow up clinical testing could keep infection rates within $5 \%$ of

548 those achieved by clinical testing of individuals (Wong et al., 2020). Following extraction, the RT-

549 qPCR and RT-ddPCR workflows used in the study required 3.5 and 7 hours, respectively, to

550 produce results. Whereas, the RT-LAMP workflow required only 1.5 hours (45 minute preparation,

55130 minute incubation, 15 minutes to read results). Additional time is required for tampon swab

552 deployment, collection, sorbate harvesting, and extraction. At ND, tampon swabs were deployed

553 at 8:00 am, retrieve at 11:00 am, and results were transmitted to the COVID Response Unit by

$5543: 00 \mathrm{pm}$. Though we only conducted the wastewater monitoring weekly, the workflow could easily

555 be modified to achieve results daily by noon. For example, a tampon swab could be deployed in

556 the sewer for 24 hours, retrieved at 8:00 am, at which time another could be deployed, and results

557 could be reported by noon at which time clinical testing could be mobilized in response. Based on

558 a 5-day incubation and 1.2 day medical seeking period (Lauer et al., 2020), Zhu et al. have

559 suggested a 6.2-day window to efficiently interrupt transmission chains (Zhu et al., 2021). The

560 tampon swab and RT-LAMP method described in this study is easily capable of producing

561 monitoring results within this window. Efficient transmission control through timely wastewater

562 results is even more important on college campuses since asymptomatic infections are more

563 prevalent among younger populations (Bjorkman et al., 2021). 


\subsection{Wastewater Monitoring Scalability and Accessibility}

566 In addition to reasonable specificity, and rapid results, the tampon swab and RT-LAMP method

567 could also afford improved accessibility to wastewater monitoring in low-resource settings. Many

568 of the COVID-19 wastewater monitoring efforts to date, including those on college campuses,

569 have made use of composite samplers and RT-qPCR techniques to detect and quantify SARS-

570 CoV-2 RNA (Ahmed et al., 2020b; Harris-Lovett et al., 2021). While these techniques have proven

571 useful for tracking COVID-19 in some communities, the expense of composite samplers and the

572 apparatus required to perform RT-qPCR greatly limits the accessibility and scalability of

573 wastewater monitoring for SARS-CoV-2. The World Health Organization has identified

574 wastewater monitoring approaches for pooled testing of high-risk lower-resource settings as a

575 critical need to expand the application of the technique (World Health Organization, 2020). While

576 we could not avoid using a kit-based RNA extraction, the method does not require a composite

577 sampler or thermal cycler for RT-qPCR, relying instead on tampons for sampling and basic lab

578 equipment including centrifuges, microcentrifuges, vortexes, and single temperature incubators

579 for swab processing and RT-LAMP testing. The per sample analytical cost was comparable

580 between RT-ddPCR (\$35) and the NEB RT-LAMP kit (\$31); however, we estimate that a self-

581 assembled RT-LAMP kit using the same primers could halve the per-sample cost once optimized.

582 Even with the off-the-shelf kit, the per capita consumables cost for the entire workflow was 583 approximately $\$ 0.25$.

\section{$585 \quad 4.5$ Limitations}

586 There are limitations that should be considered in generalizing the findings of this study. First, our

587 comparison of RT-LAMP and RT-qPCR/ddPCR leveraged samples from only two monitoring 588 sites, ND and UGA. Although we made use of raw sewage and WWTP influent samples, 589 wastewater, and therefore RT-LAMP performance, can be variable among sites. For comparison 590 with clinical surveillance, we monitored wastewater at nine ND residence halls. We note that while 
591 COVID protocols during the sampling period did not allow guests into the residence halls, it is not 592 possible to completely exclude the possible shedding of SARS-CoV-2 RNA into the residence 593 hall wastewater by non-residents. The predictive performance was variable between halls and 594 weeks and the study was not designed to further investigate these differences. The tampon swabs 595 were only deployed for a three-hour interval between 8:00 am and 11:00 am. This period 596 accounted for roughly $20 \%$ of daily domestic water use, but the performance of the workflow could 597 potentially be improved with longer deployments of the tampon swabs, assuming this does not 598 lead to increased rates of inhibition. We independently monitored the wastewater from residence 599 halls during a large and robust clinical surveillance program that featured weekly testing of every 600 single student. In the midst of such a clinical surveillance effort, the predictive performance of 601 wastewater monitoring is likely to be conservative. Nonetheless, our experience suggests that 602 tampon swabs in combination with RT-LAMP could afford a specific, rapid, cost-effective, and 603 accessible screening method for building-level wastewater monitoring. As vaccination efforts 604 continue to progress, such a monitoring method may offer a scalable approach for non-intrusive 605 screening of at-risk populations.

606

607 5. Conclusions

608 - RT-LAMP sensitivity was $57 \%$, specificity was $100 \%, 95 \%$ LOD was 76 gene copies per 609 reaction compared to SARS-CoV-2 RNA detection by RT-ddPCR.

610 - Tampon swabs combined with RT-LAMP were successfully used to detect SARS-CoV-2 611 RNA in building-level wastewater with results available the by 3 pm the same day.

612 - Over six weeks of monitoring the swab and RT-LAMP wastewater test demonstrated $61380 \%$ negative predictive value and $33 \%$ positive predictive value compared to clinical $614 \quad$ COVID-19 testing. 
615 - The consumables cost of wastewater monitoring over six by tampon swab and RT-

616 LAMP was less than $\$ 2$ per person and could likely be further reduced through a self-

617 assembled LAMP kit.

618

619 Acknowledgements

620 This work was funded in part by the UGA College of Public Health and Athens-Clarke County, the

621 University of Notre Dame COVID Response Unit, and NSF grant 2027752. We would like to thank

622 ND utilities, the ND Covid Response Unit, our local WWTP partners, Athens-Clarke county, and

623 the public utilities department for their logistical support of the work described herein.

624

625 Data Availability

626 The datasets analyzed during the current study, excluding clinical data, are available in the

627 OSF.IO repository, https://osf.io/2jdbs/ doi: 10.17605/OSF.IO/2JDBS.

628

629 Competing Interests

630 The authors declare no competing financial or non-financial interests. 

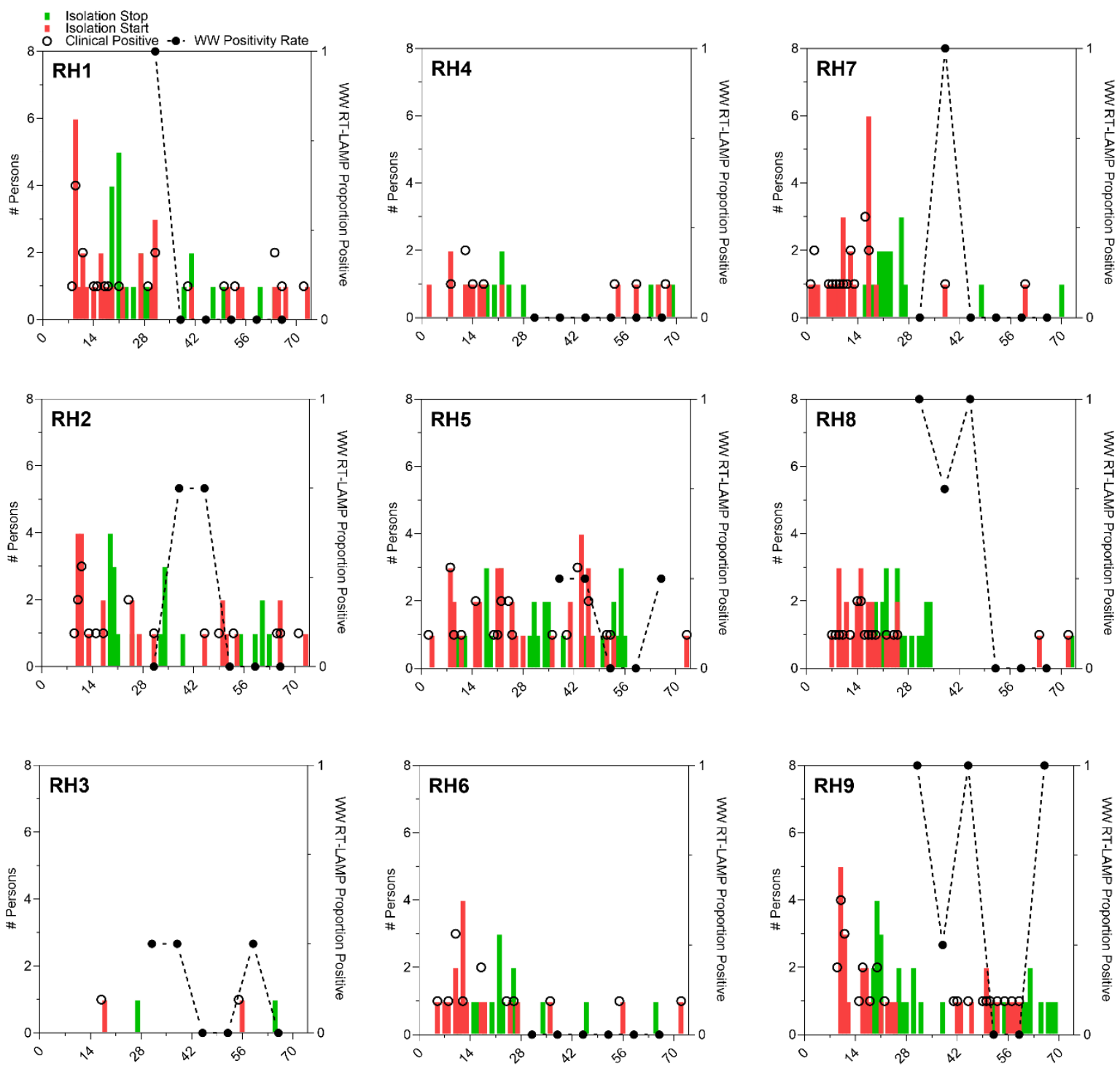

Figure 1 | Daily COVID-19 clinical positives, isolation start, and isolation stop (left y-axis), 635

636 637 compared with the proportion of RT-LAMP reactions positive (three reactions per wastewater (WW) sample; right y-axis) for SARS-CoV-2 RNA among nine residence halls over a 73 day period (x-axis) with wastewater monitoring every seven days from day 31 to 66. 
638
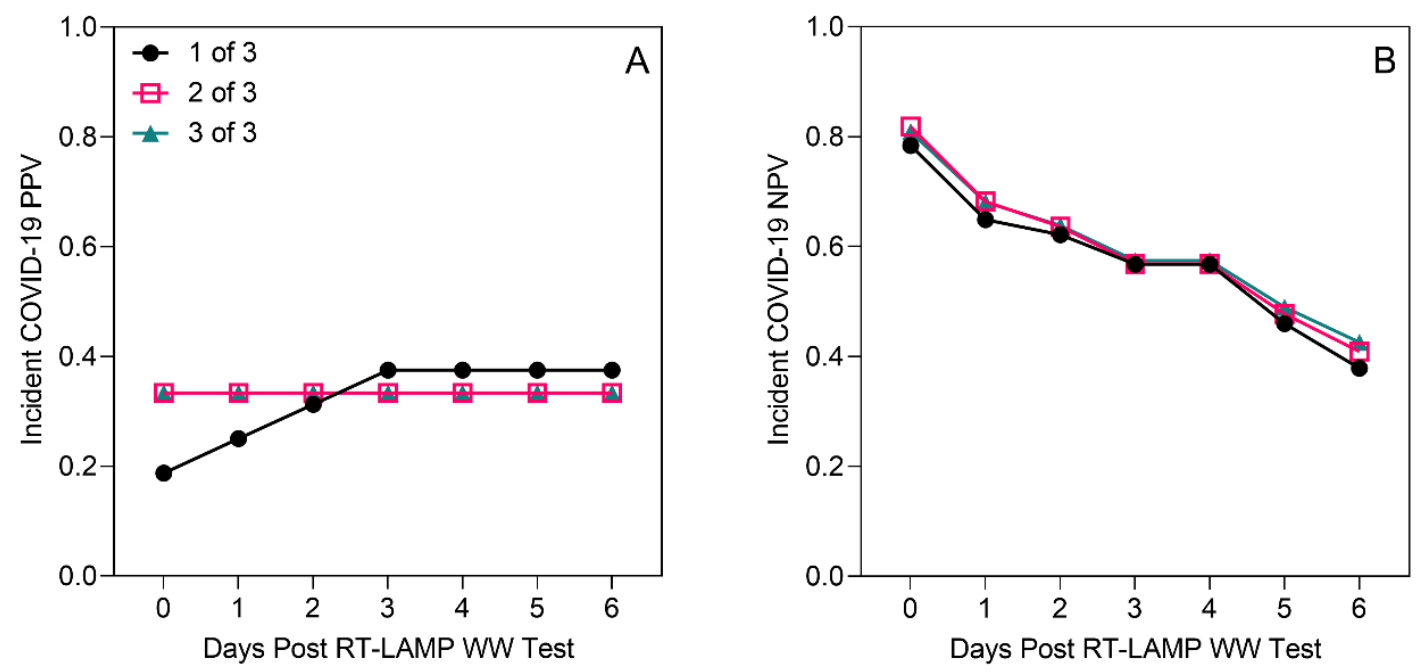

Figure 2 | Positive predictive value (PPV) (A) and negative predictive value (NPV) (B) in the seven days following wastewater monitoring by tampon swab and RT-LAMP for three different cutoff values for classification of RT-LAMP results as "positive" for SARS-CoV-2 RNA (1 of 3, 2 of 3, or 645 3 of 3 reactions positive) as observed during monitoring of wastewater from nine residence halls for six weeks. 


\section{References}

647

648

649

650

651

652

653

654

655

656

657

658

659

660

661

662

663

664

665

666

667

668

669

670

671

672

673

674

675

676

677

678

679

680

681

682

683

684

685

686

687

688

689

690

691

692

693

694

695
Ahmed, W., Angel, N., Edson, J., Bibby, K., Bivins, A., O’Brien, J.W., Choi, P.M., Kitajima, M., Simpson, S.L., Li, J., Tscharke, B., Verhagen, R., Smith, W.J.M., Zaugg, J., Dierens, L., Hugenholtz, P., Thomas, K. V., Mueller, J.F., 2020a. First confirmed detection of SARSCoV-2 in untreated wastewater in Australia: A proof of concept for the wastewater surveillance of COVID-19 in the community. Sci. Total Environ. 138764. https://doi.org/10.1016/j.scitotenv.2020.138764

Ahmed, W., Bivins, A., Bertsch, P.M., Bibby, K., Choi, P.M., Farkas, K., Gyawali, P., Hamilton, K.A., Haramoto, E., Kitajima, M., Simpson, S.L., Tandukar, S., Thomas, K., Mueller, J.F., 2020b. Surveillance of SARS-CoV-2 RNA in wastewater: Methods optimisation and quality control are crucial for generating reliable public health information. Curr. Opin. Environ. Sci. Heal. https://doi.org/10.1016/j.coesh.2020.09.003

Arons, M.M., Hatfield, K.M., Reddy, S.C., Kimball, A., James, A., Jacobs, J.R., Taylor, J., Spicer, K., Bardossy, A.C., Oakley, L.P., Tanwar, S., Dyal, J.W., Harney, J., Chisty, Z., Bell, J.M., Methner, M., Paul, P., Carlson, C.M., McLaughlin, H.P., Thornburg, N., Tong, S., Tamin, A., Tao, Y., Uehara, A., Harcourt, J., Clark, S., Brostrom-Smith, C., Page, L.C., Kay, M., Lewis, J., Montgomery, P., Stone, N.D., Clark, T.A., Honein, M.A., Duchin, J.S., Jernigan, J.A., 2020. Presymptomatic SARS-CoV-2 Infections and Transmission in a Skilled Nursing Facility. N. Engl. J. Med. 382, 2081-2090. https://doi.org/10.1056/NEJMoa2008457

Barich, D., Slonczewski, J.L., 2021. Wastewater Virus Detection Complements Clinical COVID19 Testing to Limit Spread of Infection at Kenyon College. medRxiv.

Barrett, T.J., Blake, P.A., Morris, G.K., Puhr, N.D., Bradford, H.B., Wells, J.G., 1980. Use of Moore swabs for isolating Vibrio cholerae from sewage. J. Clin. Microbiol. 11, 385-8. https://doi.org/10.1128/JCM.11.4.385-388.1980

Betancourt, W.Q., Schmitz, B.W., Innes, G.K., Prasek, S.M., Pogreba Brown, K.M., Stark, E.R., Foster, A.R., Sprissler, R.S., Harris, D.T., Sherchan, S.P., Gerba, C.P., Pepper, I.L., 2021. COVID-19 containment on a college campus via wastewater-based epidemiology, targeted clinical testing and an intervention. Sci. Total Environ. 779, 146408. https://doi.org/10.1016/j.scitotenv.2021.146408

Bivins, A., North, D., Ahmad, A., Ahmed, W., Alm, E., Been, F., Bhattacharya, P., Bijlsma, L., Boehm, A.B., Brown, J., Buttiglieri, G., Calabro, V., Carducci, A., Castiglioni, S., Cetecioglu Gurol, Z., Chakraborty, S., Costa, F., Curcio, S., De Los Reyes, F.L., Delgado Vela, J., Farkas, K., Fernandez-Casi, X., Gerba, C., Gerrity, D., Girones, R., Gonzalez, R., Haramoto, E., Harris, A., Holden, P.A., Islam, M.T., Jones, D.L., Kasprzyk-Hordern, B., Kitajima, M., Kotlarz, N., Kumar, M., Kuroda, K., La Rosa, G., Malpei, F., Mautus, M., McLellan, S.L., Medema, G., Meschke, J.S., Mueller, J., Newton, R.J., Nilsson, D., Noble, R.T., Van Nuijs, A., Peccia, J., Perkins, T.A., Pickering, A.J., Rose, J., Sanchez, G., Smith, A., Stadler, L., Stauber, C., Thomas, K., Van Der Voorn, T., Wigginton, K., Zhu, K., Bibby, K., 2020. Wastewater-Based Epidemiology: Global Collaborative to Maximize Contributions in the Fight against COVID-19. Environ. Sci. Technol. https://doi.org/10.1021/acs.est.0c02388

Bivins, A., North, D., Wu, Z., Shaffer, M., Ahmed, W., Bibby, K., 2021. Within-Day Variability of SARS-CoV-2 RNA in Municipal Wastewater Influent During Periods of Varying COVID-19 Prevalence and Positivity. medRxiv. https://doi.org/10.1101/2021.03.16.21253652v1

Bjorkman, K.K., Saldi, T.K., Lasda, E., Bauer, L.C., Kovarik, J., Gonzales, P.K., Fink, M.R., Tat, K.L., Hager, C.R., Davis, J.C., Ozeroff, C.D., Brisson, G.R., Larremore, D.B., Leinwand, L.A., McQueen, M.B., Parker, R., 2021. Higher viral load drives infrequent SARS-CoV-2 transmission between asymptomatic residence hall roommates. medRxiv.

Carrillo-Reyes, J., Barragán-Trinidad, M., Buitrón, G., 2021. Surveillance of SARS-CoV-2 in 
696

697

698

699

700

701

702

703

704

705

706

707

708

709

710

711

712

713

714

715

716

717

718

719

720

721

722

723

724

725

726

727

728

729

730

731

732

733

734

735

736

737

738

739

740

741

742

743

744

745

746 sewage and wastewater treatment plants in Mexico. J. Water Process Eng. 40, 101815. https://doi.org/10.1016/j.jwpe.2020.101815

Cevik, M., Tate, M., Lloyd, O., Maraolo, A.E., Schafers, J., Ho, A., 2021. SARS-CoV-2, SARSCoV, and MERS-CoV viral load dynamics, duration of viral shedding, and infectiousness: a systematic review and meta-analysis. The Lancet Microbe 2, e13-e22. https://doi.org/10.1016/S2666-5247(20)30172-5

Colosi, L.M., Barry, K.E., Kotay, S.M., Porter, M.D., Poulter, M.D., Ratliff, C., Simmons, W., Steinberg, L.I., Wilson, D.D., Morse, R., Zmick, P., Mathers, A.J., 2021. Development of wastewater pooled surveillance of SARS-CoV-2 from congregate living settings. Appl. Environ. Microbiol. https://doi.org/10.1128/AEM.00433-21

D’Aoust, P.M., Graber, T.E., Mercier, E., Montpetit, D., Alexandrov, I., Neault, N., Baig, A.T., Mayne, J., Zhang, X., Alain, T., Servos, M.R., Srikanthan, N., MacKenzie, M., Figeys, D., Manuel, D., Jüni, P., MacKenzie, A.E., Delatolla, R., 2021a. Catching a resurgence: Increase in SARS-CoV-2 viral RNA identified in wastewater $48 \mathrm{~h}$ before COVID-19 clinical tests and $96 \mathrm{~h}$ before hospitalizations. Sci. Total Environ. 770, 145319. https://doi.org/10.1016/j.scitotenv.2021.145319

D'Aoust, P.M., Mercier, E., Montpetit, D., Jia, J.-J., Alexandrov, I., Neault, N., Baig, A.T., Mayne, J., Zhang, X., Alain, T., Langlois, M.-A., Servos, M.R., MacKenzie, M., Figeys, D., MacKenzie, A.E., Graber, T.E., Delatolla, R., 2021b. Quantitative analysis of SARS-CoV-2 RNA from wastewater solids in communities with low COVID-19 incidence and prevalence. Water Res. 188, 116560. https://doi.org/10.1016/j.watres.2020.116560

Davó, L., Seguí, R., Botija, P., Beltrán, M.J., Albert, E., Torres, I., López-Fernández, P.Á., Ortí, R., Maestre, J.F., Sánchez, G., Navarro, D., 2021. Early detection of SARS-CoV-2 infection cases or outbreaks at nursing homes by targeted wastewater tracking. Clin. Microbiol. Infect. https://doi.org/10.1016/j.cmi.2021.02.003

Dunn, O.J., 1964. Multiple Comparisons Using Rank Sums. Technometrics 6, 241-252. https://doi.org/10.1080/00401706.1964.10490181

Elbeblaw, R., 2020. Gastrointestinal SARS CoV-2 Infection and The Dynamic of Its Detection in Stool. J. Respir. Infect. 4. https://doi.org/10.18297/jri/vol4/iss1/61

Feng, S., Roguet, A., McClary-Gutierrez, J.S., Newton, R.J., Kloczko, N., Meiman, J.G., McLellan, S.L., 2021. Evaluation of sampling frequency and normalization of SARS-CoV-2 wastewater concentrations for capturing COVID-19 burdens in the community. medRxiv preprint. https://doi.org/10.1101/2021.02.17.21251867v2

Fongaro, G., Stoco, P.H., Souza, D.S.M., Grisard, E.C., Magri, M.E., Rogovski, P., Schörner, M.A., Barazzetti, F.H., Christoff, A.P., de Oliveira, L.F.V., Bazzo, M.L., Wagner, G., Hernández, M., Rodríguez-Lázaro, D., 2021. The presence of SARS-CoV-2 RNA in human sewage in Santa Catarina, Brazil, November 2019. Sci. Total Environ. 778, 146198. https://doi.org/10.1016/j.scitotenv.2021.146198

Fox, J., 1997. Applied regression analysis, linear models, and related methods. Sage Publications, Inc.

Ganguli, A., Mostafa, A., Berger, J., Aydin, M.Y., Sun, F., Ramirez, S.A.S. de, Valera, E., Cunningham, B.T., King, W.P., Bashir, R., 2020. Rapid isothermal amplification and portable detection system for SARS-CoV-2. Proc. Natl. Acad. Sci. 117, 22727-22735. https://doi.org/10.1073/pnas.2014739117

Gibas, C., Lambirth, K., Mittal, N., Juel, M.A.I., Barua, V.B., Roppolo Brazell, L., Hinton, K., Lontai, J., Stark, N., Young, I., Quach, C., Russ, M., Kauer, J., Nicolosi, B., Chen, D., Akella, S., Tang, W., Schlueter, J., Munir, M., 2021. Implementing building-level SARSCoV-2 wastewater surveillance on a university campus. Sci. Total Environ. 782, 146749. https://doi.org/10.1016/j.scitotenv.2021.146749

Gonzalez, R., Curtis, K., Bivins, A., Bibby, K., Weir, M.H., Yetka, K., Thompson, H., Keeling, D., Mitchell, J., Gonzalez, D., 2020. COVID-19 surveillance in Southeastern Virginia using 
wastewater-based epidemiology. Water Res. 186, 116296.

https://doi.org/10.1016/j.watres.2020.116296

Gutierrez, V.C., Hassard, F., Vu, M., Leitao, R., Burczynska, B., Wildeboer, D., Stanton, I., Rahmizadeh, S., Baio, G., Garelick, H., Hofman, J., Kasprzyk-Hordern, B., Kwiatkowska, R., Majeed, A., Priest, S., Grimsley, J., Lundy, L., Singer, A.C., Cesare, M. Di, 2021. Monitoring occurrence of SARS-CoV-2 in school populations: a wastewater-based approache. medRxiv. https://doi.org/10.1101/2021.03.25.21254231

Harris-Lovett, S., Nelson, K.L., Beamer, P., Bischel, H.N., Bivins, A., Bruder, A., Butler, C., Camenisch, T.D., De Long, S.K., Karthikeyan, S., Larsen, D.A., Meierdiercks, K., Mouser, P.J., Pagsuyoin, S., Prasek, S.M., Radniecki, T.S., Ram, J.L., Roper, D.K., Safford, H., Sherchan, S.P., Shuster, W., Stalder, T., Wheeler, R.T., Korfmacher, K.S., 2021. Wastewater Surveillance for SARS-CoV-2 on College Campuses: Initial Efforts, Lessons Learned, and Research Needs. Int. J. Environ. Res. Public Health 18, 4455. https://doi.org/10.3390/ijerph18094455

Hassard, F., Lundy, L., Singer, A.C., Grimsley, J., Di Cesare, M., 2021. Innovation in wastewater near-source tracking for rapid identification of COVID-19 in schools. The Lancet Microbe 2, e4-e5. https://doi.org/10.1016/S2666-5247(20)30193-2

Johnson, R., Muller, C.J.F., Ghoor, S., Louw, J., Archer, E., Surujlal-Naicker, S., Berkowitz, N., Volschenk, M., Bröcker, L.H.L., Wolfaardt, G., Van der Walt, M., Mutshembele, A.M., Malema, S., Gelderblom, H.C., Muhdluli, M., Gray, G., Mathee, A., Street, R., 2021. Qualitative and quantitative detection of SARS-CoV-2 RNA in untreated wastewater in Western Cape Province, South Africa. South African Med. J. 111, 198. https://doi.org/10.7196/SAMJ.2021.v111i3.15154

Jones, D.L., Baluja, M.Q., Graham, D.W., Corbishley, A., McDonald, J.E., Malham, S.K., Hillary, L.S., Connor, T.R., Gaze, W.H., Moura, I.B., Wilcox, M.H., Farkas, K., 2020. Shedding of SARS-CoV-2 in feces and urine and its potential role in person-to-person transmission and the environment-based spread of COVID-19. Sci. Total Environ. 749, 141364. https://doi.org/10.1016/j.scitotenv.2020.141364

Karthikeyan, S., Ronquillo, N., Belda-Ferre, P., Alvarado, D., Javidi, T., Longhurst, C.A., Knight, R., 2021. High-Throughput Wastewater SARS-CoV-2 Detection Enables Forecasting of Community Infection Dynamics in San Diego County. mSystems 6. https://doi.org/10.1128/mSystems.00045-21

Kashi, A.H., Rosette, J. de la, Amini, E., Abdi, H., Fallah-karkan, M., Vaezjalali, M., 2020. Urinary Viral Shedding of COVID-19 and its Clinical Associations: A Systematic Review and Meta-analysis of Observational Studies. Urol. J. 17, 433-441. https://doi.org/10.22037/uj.v16i7.6248

Kitamura, K., Sadamasu, K., Muramatsu, M., Yoshida, H., 2021. Efficient detection of SARSCoV-2 RNA in the solid fraction of wastewater. Sci. Total Environ. 763, 144587. https://doi.org/10.1016/j.scitotenv.2020.144587

Kruskal, W.H., Wallis, W.A., 1952. Use of Ranks in One-Criterion Variance Analysis. J. Am. Stat. Assoc. 47, 583-621. https://doi.org/10.1080/01621459.1952.10483441

Lalli, M.A., Langmade, J.S., Chen, X., Fronick, C.C., Sawyer, C.S., Burcea, L.C., Wilkinson, M.N., Fulton, R.S., Heinz, M., Buchser, W.J., Head, R.D., Mitra, R.D., Milbrandt, J., 2021. Rapid and Extraction-Free Detection of SARS-CoV-2 from Saliva by Colorimetric ReverseTranscription Loop-Mediated Isothermal Amplification. Clin. Chem. 67, 415-424. https://doi.org/10.1093/clinchem/hvaa267

Lauer, S.A., Grantz, K.H., Bi, Q., Jones, F.K., Zheng, Q., Meredith, H.R., Azman, A.S., Reich, N.G., Lessler, J., 2020. The Incubation Period of Coronavirus Disease 2019 (COVID-19) From Publicly Reported Confirmed Cases: Estimation and Application. Ann. Intern. Med. 172, 577-582. https://doi.org/10.7326/M20-0504

Lavezzo, E., Franchin, E., Ciavarella, C., Cuomo-Dannenburg, G., Barzon, L., Del Vecchio, C., 
798

799

800

801

802

803

804

805

806

807

808

809

810

811

812

813

814

815

816

817

818

819

820

821

822

823

824

825

826

827

828

829

830

831

832

833

834

835

836

837

838

839

840

841

842

843

844

845

846

847

848
Rossi, L., Manganelli, R., Loregian, A., Navarin, N., Abate, D., Sciro, M., Merigliano, S., De Canale, E., Vanuzzo, M.C., Besutti, V., Saluzzo, F., Onelia, F., Pacenti, M., Parisi, S.G., Carretta, G., Donato, D., Flor, L., Cocchio, S., Masi, G., Sperduti, A., Cattarino, L., Salvador, R., Nicoletti, M., Caldart, F., Castelli, G., Nieddu, E., Labella, B., Fava, L., Drigo, M., Gaythorpe, K.A.M., Brazzale, A.R., Toppo, S., Trevisan, M., Baldo, V., Donnelly, C.A., Ferguson, N.M., Dorigatti, I., Crisanti, A., 2020. Suppression of a SARS-CoV-2 outbreak in the Italian municipality of Vo'. Nature 584, 425-429. https://doi.org/10.1038/s41586-0202488-1

Li, B., Di, D.Y.W., Saingam, P., Jeon, M.K., Yan, T., 2021. Fine-Scale Temporal Dynamics of SARS-CoV-2 RNA Abundance in Wastewater during A COVID-19 Lockdown. Water Res. 197, 117093. https://doi.org/10.1016/j.watres.2021.117093

Liu, P., Ibaraki, M., Tassell, J. Van, Geith, K., Cavallo, M., Kann, R., Moe, C., 2020. A Novel COVID-19 Early Warning Tool: Moore Swab Method for Wastewater Surveillance at an Institutional Level. medRxiv.

Lopman, B., Liu, C.Y., Le Guillou, A., Handel, A., Lash, T.L., Isakov, A.P., Jenness, S.M., 2021. A modeling study to inform screening and testing interventions for the control of SARSCoV-2 on university campuses. Sci. Rep. 11, 5900. https://doi.org/10.1038/s41598-02185252-z

Mahmoud, S.A., Ibrahim, E., Ganesan, S., Thakre, B., Teddy, J.G., Preeti, R., 2021. Evaluation of RNA extraction free method for detection of SARS-COV-2 in salivary samples for mass screening for COVID-19. medRxiv. https://doi.org/10.1101/2021.03.15.21253570

Mann, H.B., Whitney, D.R., 1947. On a Test of Whether one of Two Random Variables is Stochastically Larger than the Other. Ann. Math. Stat. 18, 50-60. https://doi.org/10.1214/aoms/1177730491

McDonald, J.H., 2015. Handbook of Biological Statistics, 3rd ed. ed. Sparky House Publishing, Baltimore, Maryland.

Medema, G., Heijnen, L., Elsinga, G., Italiaander, R., Brouwer, A., 2020. Presence of SARSCoronavirus-2 RNA in Sewage and Correlation with Reported COVID-19 Prevalence in the Early Stage of the Epidemic in The Netherlands. Environ. Sci. Technol. Lett. 7, 511-516. https://doi.org/10.1021/acs.estlett.0c00357

Monod, M., Blenkinsop, A., Xi, X., Hebert, D., Bershan, S., Tietze, S., Baguelin, M., Bradley, V.C., Chen, Y., Coupland, H., Filippi, S., Ish-Horowicz, J., McManus, M., Mellan, T., Gandy, A., Hutchinson, M., Unwin, H.J.T., van Elsland, S.L., Vollmer, M.A.C., Weber, S., Zhu, H., Bezancon, A., Ferguson, N.M., Mishra, S., Flaxman, S., Bhatt, S., Ratmann, O., 2021. Age groups that sustain resurging COVID-19 epidemics in the United States.

Science (80-. ). 371, eabe8372. https://doi.org/10.1126/science.abe8372

Nemudryi, A., Nemudraia, A., Wiegand, T., Surya, K., Buyukyoruk, M., Cicha, C., Vanderwood, K.K., Wilkinson, R., Wiedenheft, B., 2020. Temporal Detection and Phylogenetic Assessment of SARS-CoV-2 in Municipal Wastewater. Cell Reports Med. 1, 100098. https://doi.org/10.1016/j.xcrm.2020.100098

Notomi, T., 2000. Loop-mediated isothermal amplification of DNA. Nucleic Acids Res. 28, 63e 63. https://doi.org/10.1093/nar/28.12.e63

Ongerth, J.E., Danielson, R.E., 2020. RT qLAMP--Direct Detection of SARS-CoV-2 in Raw Sewageitle. medRxiv.

Oran, D.P., Topol, E.J., 2020. Prevalence of Asymptomatic SARS-CoV-2 Infection. Ann. Intern. Med. 173, 362-367. https://doi.org/10.7326/M20-3012

Paltiel, A.D., Zheng, A., Walensky, R.P., 2020. Assessment of SARS-CoV-2 Screening Strategies to Permit the Safe Reopening of College Campuses in the United States. JAMA Netw. Open 3, e2016818. https://doi.org/10.1001/jamanetworkopen.2020.16818

Parikh, R., Mathai, A., Parikh, S., Chandra Sekhar, G., Thomas, R., 2008. Understanding and using sensitivity, specificity and predictive values. Indian J. Ophthalmol. 56, 45. 
849

850

851

852

853

854

855

856

857

858

859

860

861

862

863

864

865

866

867

868

869

870

871

872

873

874

875

876

877

878

879

880

881

882

883

884

885

886

887

888

889

890

891

892

893

894

895

896

897

898

899

https://doi.org/10.4103/0301-4738.37595

Park, S., Lee, C.-W., Park, D.-I., Woo, H.-Y., Cheong, H.S., Shin, H.C., Ahn, K., Kwon, M.-J., Joo, E.-J., 2020. Detection of SARS-CoV-2 in Fecal Samples From Patients With Asymptomatic and Mild COVID-19 in Korea. Clin. Gastroenterol. Hepatol. https://doi.org/10.1016/j.cgh.2020.06.005

Peccia, J., Zulli, A., Brackney, D.E., Grubaugh, N.D., Edward, H., Casanovas-massana, A., Ko, A.I., Malik, A.A., Wang, D., 2020. SARS-CoV-2 RNA concentrations in primary municipal sewage sludge as a leading indicator of COVID-19 outbreak dynamics 1.

Reukers, D.F.M., van Boven, M., Meijer, A., Rots, N., Reusken, C., Roof, I., van GageldonkLafeber, A.B., van der Hoek, W., van den Hof, S., 2021. High infection secondary attack rates of SARS-CoV-2 in Dutch households revealed by dense sampling. Clin. Infect. Dis. https://doi.org/10.1093/cid/ciab237

Saguti, F., Magnil, E., Enache, L., Churqui, M.P., Johansson, A., Lumley, D., Davidsson, F., Dotevall, L., Mattsson, A., Trybala, E., Lagging, M., Lindh, M., Gisslén, M., Brezicka, T., Nyström, K., Norder, H., 2021. Surveillance of wastewater revealed peaks of SARS-CoV-2 preceding those of hospitalized patients with COVID-19. Water Res. 189, 116620. https://doi.org/10.1016/j.watres.2020.116620

Schang, C., Crosbie, N., Monica, N., Poon, R., Wang, M., Jex, A., Scales, P.J., Schmidt, J., Thorley, B., Henry, R., Kolotelo, P., Langeveld, J., Schilperoort, R., Shi, B., Einsiedel, S., Thomas, M., Black, J.F.P., Wilson, S., McCarthy, D., 2020. Passive sampling of viruses for wastewater-based epidemiology: a case-study of SARS-CoV-2. https://doi.org/10.13140/RG.2.2.24138.39367

Schermer, B., Fabretti, F., Damagnez, M., Di Cristanziano, V., Heger, E., Arjune, S., Tanner, N.A., Imhof, T., Koch, M., Ladha, A., Joung, J., Gootenberg, J.S., Abudayyeh, O.O., Burst, V., Zhang, F., Klein, F., Benzing, T., Müller, R.-U., 2020. Rapid SARS-CoV-2 testing in primary material based on a novel multiplex RT-LAMP assay. PLoS One 15, e0238612. https://doi.org/10.1371/journal.pone.0238612

Spurbeck, R., Minard-Smith, A.T., Catlin, L.A., 2021. Applicability of Neighborhood and Building Scale Wastewater-Based Genomic Epidemiology to Track the SARS-CoV-2 Pandemic and other Pathogens. medRxiv. https://doi.org/10.1101/2021.02.18.21251939v1

Tian, P., Yang, D., Shan, L., Wang, D., Li, Q., Gorski, L., Lee, B.G., Quiñones, B., Cooley, M.B., 2017. Concurrent Detection of Human Norovirus and Bacterial Pathogens in Water Samples from an Agricultural Region in Central California Coast. Front. Microbiol. 8. https://doi.org/10.3389/fmicb.2017.01560

Tjur, T., 2009. Coefficients of Determination in Logistic Regression Models-A New Proposal: The Coefficient of Discrimination. Am. Stat. 63, 366-372.

https://doi.org/10.1198/tast.2009.08210

Travis, S.A., Best, A.A., Bochniak, K.S., Dunteman, N.D., Fellinger, J., Folkert, P.D., Koberna, T., Kopek, B.G., Krueger, B.P., Pestun, J., Pikaart, M.J., Sabo, C., Schuitema, A.J., 2021. Providing a safe, in-person, residential college experience during the COVID-19 pandemic. medRxiv.

Walsh, K.A., Jordan, K., Clyne, B., Rohde, D., Drummond, L., Byrne, P., Ahern, S., Carty, P.G., O'Brien, K.K., O'Murchu, E., O'Neill, M., Smith, S.M., Ryan, M., Harrington, P., 2020. SARS-CoV-2 detection, viral load and infectivity over the course of an infection. J. Infect. 81, 357-371. https://doi.org/10.1016/j.jinf.2020.06.067

Wang, X., Zheng, J., Guo, L., Yao, H., Wang, L., Xia, X., Zhang, W., 2020. Fecal viral shedding in COVID-19 patients: Clinical significance, viral load dynamics and survival analysis. Virus Res. 289, 198147. https://doi.org/10.1016/j.virusres.2020.198147

Wong, T.E., Thurston, G.M., Barlow, N., Cahill, N., Carichino, L., Maki, K., Ross, D., Schneider, J., 2020. Evaluating the Sensitivity of SARS-CoV-2 Infection Rates on College Campuses to Wastewater Surveillance. medRxiv. https://doi.org/10.1101/2020.10.09.20210245 
900

901

902

903

904

905

906

907

908

909

910

911

912

913

914

915

916

917

918

919

920

921

922

923

924

925

926
World Health Organization, 2020. Status of environmental surveillance for SARS-CoV-2 virus. Geneva, Switzerland.

Wu, F., Zhang, J., Xiao, A., Gu, X., Lee, W.L., Armas, F., Kauffman, K., Hanage, W., Matus, M., Ghaeli, N., Endo, N., Duvallet, C., Poyet, M., Moniz, K., Washburne, A.D., Erickson, T.B., Chai, P.R., Thompson, J., Alm, E.J., 2020. SARS-CoV-2 Titers in Wastewater Are Higher than Expected from Clinically Confirmed Cases. mSystems 5. https://doi.org/10.1128/mSystems.00614-20

Wyllie, A.L., Fournier, J., Casanovas-Massana, A., Campbell, M., Tokuyama, M., Vijayakumar, P., Warren, J.L., Geng, B., Muenker, M.C., Moore, A.J., Vogels, C.B.F., Petrone, M.E., Ott, I.M., Lu, P., Venkataraman, A., Lu-Culligan, A., Klein, J., Earnest, R., Simonov, M., Datta, R., Handoko, R., Naushad, N., Sewanan, L.R., Valdez, J., White, E.B., Lapidus, S., Kalinich, C.C., Jiang, X., Kim, D.J., Kudo, E., Linehan, M., Mao, T., Moriyama, M., Oh, J.E., Park, A., Silva, J., Song, E., Takahashi, T., Taura, M., Weizman, O.-E., Wong, P., Yang, Y., Bermejo, S., Odio, C.D., Omer, S.B., Dela Cruz, C.S., Farhadian, S., Martinello, R.A., Iwasaki, A., Grubaugh, N.D., Ko, A.I., 2020. Saliva or Nasopharyngeal Swab Specimens for Detection of SARS-CoV-2. N. Engl. J. Med. 383, 1283-1286. https://doi.org/10.1056/NEJMc2016359

Ye, Y., Ellenberg, R.M., Graham, K.E., Wigginton, K.R., 2016. Survivability, Partitioning, and Recovery of Enveloped Viruses in Untreated Municipal Wastewater. Environ. Sci. Technol. 50, 5077-5085. https://doi.org/10.1021/acs.est.6b00876

Zhang, Y., Ren, G., Buss, J., Barry, A.J., Patton, G.C., Tanner, N.A., 2020. Enhancing colorimetric loop-mediated isothermal amplification speed and sensitivity with guanidine chloride. Biotechniques 69, 178-185. https://doi.org/10.2144/btn-2020-0078

Zhu, Y., Oishi, W., Maruo, C., Saito, M., Chen, R., Kitajima, M., Sano, D., 2021. Early warning of COVID-19 via wastewater-based epidemiology: potential and bottlenecks. Sci. Total Environ. 767, 145124. https://doi.org/10.1016/j.scitotenv.2021.145124 